\title{
Supercritical Fluid Extraction: Present Status and Prospects
}

\author{
By Jerry W. King \\ New Crops and Processing Technology Unit \\ National Center for Agricultural Utilization Research \\ Agricultural Research Service/USDA \\ 1815 N. University Street Peoria, IL 61604, USA \\ Tel: 001-309-681-6203, Fax: 001-309-681-6686, E-mail: kingjw@mail.ncaur.usda.gov
}

\section{CONTENTS}

1. Introduction.

2. Principles for the analytical SFE of lipids.

3. Current instrumentation trends.

4. Critical parameters for successful SFE.

5. Application of analytical SFE to fats, oils, and lipids. References.

\section{RESUMEN}

Extracción con fluidos supercríticos: Presente y perspectivas.

Este artículo revisa el presente y el uso futuro de la extracción con fluidos supercríticos (SFE), principalmente dióxido de carbono $\left(\mathrm{CO}_{2}\right)$ benigno para el ambiente. La extracción con fluidos supercríticos se desarrolló como aplicación analítica a mediados de los años 80 como respuesta al deseo de reducir el uso de disolventes orgánicos en el ambiente del laboratorio, y se está convirtiendo en un método estándar con respecto a la preparación y análisis de muestras conteniendo lípidos. Actualmente, la analítica de SFE es predominantemente aplicada en modo "off-line", usando modos de extracción secuenciales y paralelos. Dependiendo de la configuración de la instrumentación, se pueden llegar a preparar diariamente hasta 24 muestras en un solo aparato. La SFE tiene otras ventajas, como el procesamiento de analitos sensibles térmicamente y una rápida cinética de extracción del analito en comparación con la extracción con disolventes líquidos. El capitulo describe no solamente ejemplos de la analítica de SFE en grasas y aceites, sino también de solutos volátiles de varios tipos de muestras. Finalmente, la relevancia de la analítica SFE en el procesamiento con fluidos supercríticos ha sido documentada con ejemplos de nuestra investigación que utiliza un método combinatorio para optimizar las condiciones del proceso.

PALABRAS-CLAVE: Aceites - Análisis - Fluido supercrítico - Grasas -Lípidos - Preparación.

\section{SUMMARY}

Supercritical fluid extraction: Present status and prospects.

Supercritical extraction (SFE), using primarily environmentally-benign carbon dioxide $\left(\mathrm{CO}_{2}\right)$ as the extracting agent, is reviewed with respect to its present status and future use. SFE was developed for analytical application in the mid 1980 's in response to the desire to reduce the use of organic solvents in the laboratory environment and is becoming a standard method for the preparation and analysis of lipid-containing sample matrices. Currently, analytical SFE is predominately practiced in the off-line mode, using both sequential and parallel extraction modes. Depending on the instrumental configuration, the preparation of up to 24 samples can be accomplished on one instrument on a daily basis. Several other benefits can be achieved using SFE, such as the processing of thermally-sensitive analytes and rapid analyte extraction kinetics relative to extraction with liquid solvents. Examples are provided not only of the analytical SFE of oils and fats, but of volatile solutes from an array of sample types. Finally, the relevance of analytical SFE to processing with supercritical fluids (SFs) is documented using examples from our own research involving a combinatorial approach to optimising processing conditions.

KEY-WORDS: Analysis - Fats - Lipids - Oils - Preparation - Supercritical fluid

\section{INTRODUCTION}

Modern methodology for fats, oils, and related lipid analysis must include both extraction and sample preparation methods as a key steps in analysis development. Techniques such as the Soxhlet method and its many variants have been used since 1906 by chemists. This technique as well as liquid-liquid separator funnel partition methods have been the dominant techniques used by analysts to isolate lipid species from sample matrices for over ninety years. Accompanying these techniques has been the use of a plethora of organic solvents as extractants or partitioning phases. However, beginning in the 1990's, regulatory legislation in the United States, such as EPA Pollution Prevention Act, the Superfund Amendments and Reauthorization Act (SARA); Resource, the Conservation and Recovery Act (RCRA), and Montreal protocols have focussed on advocating a reduction in the use of organic solvents that are harmful to the environment.

Aside from these formal legislative mandates, there is good reason to consider the elimination or minimization of organic solvent use in the chemical laboratory. Practical everyday experience suggests that if alternatives could be found to using organic solvents for extraction or partition in chemical analysis, that the advantages noted in Table I could be realized. Analytical SFE is but one of several alternative methods that address some of these problems. Associated techniques that can eliminate or substantially reduce the dependence on organic solvents in the laboratory environment include: microwave extraction, pressurized fluid extraction, solid phase microfibre extraction, solid phase 
Table I

\section{Advantages in using supercritical fluids for extraction and sample preparation}

Storage and disposal costs associated with used solvents

Disposal of used solvent containers

Exposure of laboratory personnel to harmful solvents

Problems associated with collection/storage of waste solvents

Tracking of waste solvents (i.e. cradle to grave responsibility)

Disposal of used solvent containers

extraction, membranes, and immunoassay-based methods (Beier and Stanker 1996). In addition, there is a trend towards the minaturization of previously developed methods, i.e. Soxhlet extraction, for reducing reagent use during chemical analysis.

Besides the ecological benefits of using supercritical fluids, particularly supercritical carbon dioxide $\left(\mathrm{SC}-\mathrm{CO}_{2}\right)$ (Lee and Markides 1990), there are other advantages to using SFE. SF mass transport properties, such as fluid and analyte diffusion coefficients in supercritical fluids, are greater in supercritical fluid media than conventional liquid solvents (Wenclawiak 1992), which results in faster extraction fluxes and a substantial reduction in extraction time. Replacement of expensive, high purity organic solvents by $\mathrm{SC}-\mathrm{CO}_{2}$ can also result in a cost savings, particularly if one elects to purify a industrial grade of $\mathrm{CO}_{2}$ for analytical purposes (Hopper et al. 1995). In addition, SC- $\mathrm{CO}_{2}$ also provides a safe, nonflammable medium, devoid of the presence of oxygen, with which to conduct extractions of thermally-labile and oxygen-sensitive analytes. Finally, using SFE, the overall complexity of the analytical method may also be reduced.

In this succinct review, the focus has been placed on the analytical SFE of fats, oils, and related lipid species, in keeping with the content of Grasas y Aceites. As noted in the title, an emphasis on the present status of the field and its future will be discussed. There are several excellent books that describe the fundamentals of the technique (Taylor 1996; Luque de Castro et al. 1994), including several reviews by the author (King et al. 1993a; King 1998a), to which the reader is referred. On-line SFE, or SFE coupled with other analytical methodology, is only marginally covered, since this analysis format is not routinely used except for specific analysis problems. An emphasis on the application of analytical SFE for routine determination of fat and oil content is described in detail, as well as the problem attendant in extracting individual lipid classes via SFE without the aid of sorbent technology. Examples will be cited that illustrate the advantage of using SFE for the analysis of volatile compounds generated from lipid-containing samples, and the more recent coupling of enzyme reactions in-situ for methyl ester and fat soluble vitamin analysis. The chapter will conclude with a discussion of future trends in the utilization of SFE, in particular the use of analytical instrumentation for optimising processing conditions utilizing SFs, as well as the status of "official" methods which employ $\mathrm{SC}-\mathrm{CO}_{2}$ extraction for the analysis of lipid analytes.

\section{PRINCIPLES FOR THE ANALYTICAL SFE OF LIPIDS}

Several guiding principles can be utilized to affect the extraction of lipids, particularly the quantitative extraction of fats and oils. These principles are as follows: optimising the solubility of lipids in $\mathrm{SC}-\mathrm{CO}_{2}$, enriching and fractionating with respect to a particular target lipid analyte, and appreciating the role of extraction kinetics in recovering lipids from sample matrices. These principles will be discussed below.

Considerable data is now available on the solubility of seed oils, pure triglycerides, and lipids in $\mathrm{SC}-\mathrm{CO}_{2}$ over a range of pressures and temperatures. Perhaps the most detailed and comprehensive studies are those of Friedrich and Pryde (1984) and Stahl et al. (1987), since they encompass the high pressure and temperature region, where very high oil solubilities in $\mathrm{SC}-\mathrm{CO}_{2}$ are found. Figure 1 illustrates the dependence of soybean oil triglyceride solubility in $\mathrm{SC}-\mathrm{CO}_{2}$ as a function of temperature and pressure. Relatively low weight percent solubilities in $\mathrm{SC}-\mathrm{CO}_{2}$ are found for triglycerides (5 wt. \%) for the 40 and $50^{\circ} \mathrm{C}$ isotherms. Hence as the temperature is increased from 50 to $60^{\circ} \mathrm{C}$, there is a pronounced increase in triglyceride solubility at pressures above 800 bar, resulting in solubilities approaching $15 \mathrm{wt}$ \%. A further increase in temperature obviously enhances oil solubility substantially as shown in

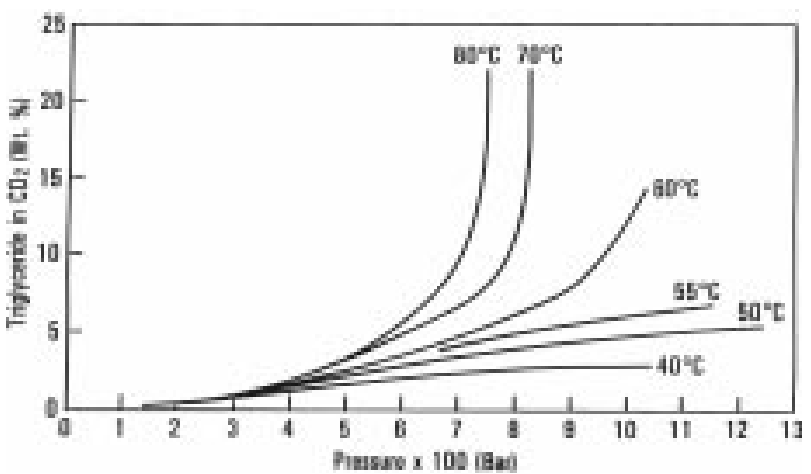

Figure 1

Solubility of soybean oil triglycerides in $\mathrm{SC}-\mathrm{CO}_{2}$ as function of temperature and pressure. 
Figure 1, resulting in solubilities that exceed $40 \mathrm{wt} . \%$ in SC- $\mathrm{CO}_{2}$ at pressures approaching 700 bar. These solubility trends for oils in $\mathrm{SC}-\mathrm{CO}_{2}$ have been employed by many researchers (Taylor et al. 1997) to perform oil and fat extractions using $\mathrm{SC}-\mathrm{CO}_{2}$ above 600 bar and temperatures from $80-100^{\circ} \mathrm{C}$, on many different sample types. Further, the above pressure/temperature parameters have influenced the design of commercial SFE instrumentation, since most current units being capable of delivering $\mathrm{SC}-\mathrm{CO}_{2}$ at pressures up to 700 bar.

As noted above, the ascent of the solubility curve (i.e., wt.\% solubility vs. pressure) is important in optimising the conditions for fat and oil extractions. This fact has been noted by King and Friedrich (1990) and used to develop a correlation between the solubility parameter of the solute and the reduced density of the extraction fluid at which its optimum solubility would be realized in a supercritical fluid. Table II tabulates these values for lipid solutes such as triglycerides, sterols, etc. Note that there is a general trend in that higher reduced densities are required to maximize the solubility of more polar lipid species. Table II indicates that a reduced density of 2.22 is required for maximizing the solubility of triglycerides, the major constituents of seed oils, in a critical fluid.

The above optimal solubility conditions apply in general to many different types of lipids. More on the

Table II

Solubility parameters for lipid types found in seed oils and the reduced densities. Required to optimise extraction of these lipid species

\begin{tabular}{lcc}
\hline \multicolumn{1}{c}{ Compounds } & Solubility parameter $^{1}$ & Reduced density $^{\prime}$ \\
\hline Hydrocarbons & 8.34 & 2.08 \\
Carotenoids & 8.72 & 2.17 \\
Tocopherols & 8.86 & 2.21 \\
Triglycerides & 8.91 & 2.22 \\
Ubiquinones & 9.08 & 2.26 \\
Fatty acids & 9.10 & 2.27 \\
Diglycerides & 9.45 & 2.35 \\
Sterols & 9.52 & 2.37 \\
Monoglycerides & 10.2 & 2.54 \\
\hline
\end{tabular}

${ }^{1}$ In units of $\mathrm{cal}^{1 / 2 /} \mathrm{cc}^{3 / 2}$

Table III

Sorbents used for fractionating lipid mixtures in SFE

\begin{tabular}{ll}
\hline Aluminas & Silica gel \\
Silicas & Florisil \\
Celite & Hydromatrix \\
Silylated & Synthetic resins \\
\hline
\end{tabular}

utility of the solubility parameter approach as applied to analytical SFE can be found from the theoretical treatment of King (1989). Table II also indicates that many lipid solutes have similar solubility parameters, making their separation by SFE difficult. This is found to be true in practice, since even when altering the density of the extracting fluid, an extract having a mixed lipid composition will generally result. This can be overcome by integrating sorbents into the extraction cell with the sample, or in-line after the extraction cell, to enhance the separation of similar lipid species. Table III lists some sorbents that have been used for fractionating lipids dissolved in $\mathrm{SC}-\mathrm{CO}_{2}$ and $\mathrm{SC}-\mathrm{CO}_{2}$-cosolvent mixtures. Using this approach, tocopherols (King et al. 1996), phospholipids (Taylor et al. 2000), phystosterols (Snyder et al. 1999) et cetera have been enriched by SFE/supercritical fluid fractionation (SFF).

The kinetics of lipid removal from a sample matrix follow similar trends for other solutes dissolving in $\mathrm{SC}-\mathrm{CO}_{2}$. This is nicely illustrated in Figure 2 for the extraction of fat from a low fat, hydrophilic ham matrix containing over $70 \%$ by weight of water. Initially the extraction kinetics are governed by the solubility of the fat in $\mathrm{SC}-\mathrm{CO}_{2}$, that is to say, there is an approximately linear dependence of fat removal into $\mathrm{SC}-\mathrm{CO}_{2}$ from the low fat ham matrix. This gives way to a transition region in which the removal of lipid becomes rate limiting, followed by an asymptotic approach to the final lipid content with passage of the extraction fluid $\left(\mathrm{SC}-\mathrm{CO}_{2}\right)$. Such extraction curves have been modelled by several investigators and generalized in a "hot ball" kinetic model by Bartle et al. (1990).

\section{CURRENT INSTRUMENTATION TRENDS}

Commercial SFE instrumentation has largely been developed in the USA and marketed throughout the world. During the early 1990's, there

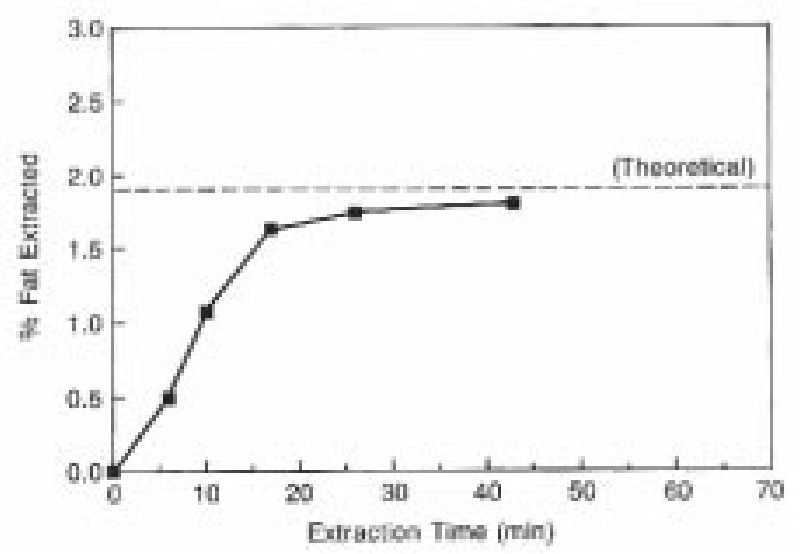

Figure 2

Rate of extraction for fat from an imported, low fat ham sample with $\mathrm{SC}-\mathrm{CO}_{2}$ at $34.5 \mathrm{MPa}$ and $80^{\circ} \mathrm{C}$. 
was a considerable "shake down" in terms of the number of companies offering SFE, both off-line and on-line. In this section only modules specifically designed and currently available for analytical SFE are described. The principles of analytical SFE are discussed in sufficient detail (Hawthorne and King 1999) that those wishing to build their own equipment can often do so at minimal expense. Larger scale bench top SFE instrumentation is described by King (1995a) which bridges the gap between large sample SFE for analytical purposes and process development evaluation.

Isco Inc. (Lincoln, Nebraska, USA) was one of the first companies to address the off-line SFE market. Two basic modules have been offered for sometime now: the Model SFX 2-10 and SFX 220. Both units have extraction fluids delivered by syringe pumps of varying capacity and pressure ranges, although the 5000 and 10,000 psi pump modules are normally purchased for use with the SFE modules. Extraction cells of $0.5,2.5$, and $10 \mathrm{~mL}$ are offered in three different cell materials: stainless steel, aluminium, and a high temperature compatible polymeric composition ( $9 \mathrm{~mL}$ disposable cartridges). Although the SFX 2-10 module is entirely manual in operation, the extraction cells can be sealed without the need of wrenches (hand tightened); both of the above modules permitting two extractions to be conducted simultaneously in parallel. Depressurisation of the solute-laden fluid is normally accomplished through the use of either a fixed flow rate or adjustable flow rate, heated coaxial back pressure restrictors. Control of the fluid delivery flow rate, extraction cartridge temperature, and restrictor temperature is achieved by microprocessor control. The SFX 220 is an automated version of the SFX 2-10 which permits automated valve operation for increase sample throughput.

One of the advantages of the above units is their modularity which permits the analyst to design and alter their extraction unit. Co-solvents are delivered with the aid of an additional pump through the microprocessor controller. There is considerable flexibility in collecting the extract; both neat and solvent-based collection tubes can be interfaced with the coaxial heated restrictors. The analyst also has the advantage of designing about any type of collection system with these units, including the use of sorbent-laden cartridges for on-line collection of lipids and volatiles for further sample preparation or off-line analysis.

Isco also offers the Model SFX 3560 which permits up to 24 samples to be extracted sequentially. This module which can operate unattended overnight is controlled through an interactive 80x24 microprocessor display which allows not only high throughput analysis, but automated method development as well. A programmable fluid "wash" cycle between each extraction is an integral part of the instrument's operation, and both static and dynamic extraction modes can be performed on individual samples. Extractions can be performed up to 10.000 psi and $150^{\circ} \mathrm{C}$. Extract collection is accomplished using empty or solvent-filled vials using an automated, feed back controlled heated restrictor to prevent icing. To aid in extract collection, the $20 \mathrm{~mL}$ glass tubes used for collection can be-cooled as low as $-20^{\circ} \mathrm{C}$ as well as pressurized above ambient conditions. It is also possible to interface the Isco Model SFX 3560 to other instrumentation such as a Fourier Transform infrared spectrometer for trans fatty acid analysis. This will be described further in the application section.

Recently Isco has offered a relative low cost, Fast Fat Extractor system specifically made for fat analysis. Extraction fluid is continuously delivered through a cooled pump head, thereby avoiding intermittent cessation of $\mathrm{CO}_{2}$ flow which occurs with the above instrumentation. An LCD-based graphics display, available in English-Spanish-FrenchGerman allows for control of extraction parameters. Each module permits the extraction in parallel of two samples, however additional modules (up to two) can be added and serviced from a single pump unit. Extractions can be conducted up to 10,000 psi and $150^{\circ} \mathrm{C}$

Applied Separations, Inc. (Allentown, PA) offers several extraction units based upon a United States Department of Agriculture (USDA) prototype (King 1995a; Maxwell et al. 1992) that offer considerable flexibility with respect to sample size and experimental design. These units can be purchased as single modules (the Speed 2 or 4 ) with the capability of extracting 2-4 samples in parallel. SFEs at higher temperatures $\left(250^{\circ} \mathrm{C}\right)$ and up to $10.000 \mathrm{psi}$ are possible with these units. Extractor vessel sizes can range from several $\mathrm{mL}$ to one liter if required. Higher and variable flow rates are possible when using these units, since an adjustable micrometering valve (Snaptight, Erie, Pennsylvania, USA) and a Haskel liquid booster pump (Haskel Inc., Burbank, California, USA) are an integral part of the unit's design.

The analyst has considerable choice with respect to the type of extract collection system that can be employed with the Speed units. One of the integral designs that can be mated to a Speed unit is shown in Figure 3. Although the pictured off-line collection/ processing systems are designed for isolating trace toxicant analytes via SFE, these same sorbent-based collection systems can be used for fractionating lipids that are extracted from natural sample matrices. A variation of this design has also been employed by Snyder and King (1994) for collecting volatile compounds from lipid degradation studies. 


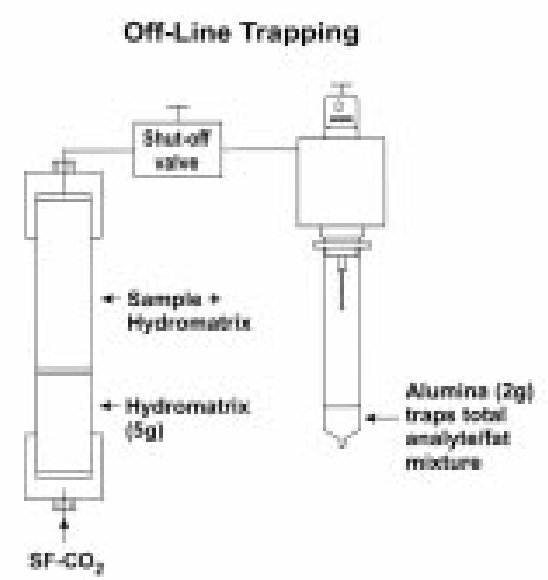

Figure 3

Supercritical fluid extraction collection system configured for off-line and in-line trapping.

Leco Corporation (St. Joseph, Michigan, USA) is now offering a second version of their Total Fat Analyzer designated the Model TFE 2000. Although lacking the modularity of the above-described instrumentation, the unit is carefully designed (and marketed) for total fat/oil determination using $\mathrm{SC}-\mathrm{CO}_{2}$ as the extraction agent. The unit accommodates $10 \mathrm{~mL}$ extraction cells and operates up to $10.000 \mathrm{psi}$ and $150^{\circ} \mathrm{C}$. Flow rates from 0-5 $\mathrm{L} / \mathrm{min}$ (expanded $\mathrm{CO}_{2}$ flow rate) are regulated using heated variable restrictors. A single module will accommodate up to 3 extraction cells, but the units can be "piggybacked" to allow extraction of up to 24 samples in parallel. As with the Isco instrumentation, the extraction cells are hand tightenable. The unit features an internal pump head cooler alleviating the analyst of the cost of an external cooling circulator.

With all of the above instrumentation, $\mathrm{CO}_{2}$ is the extraction fluid of choice due to the high solubility of lipids in this medium. For total fat or oil extractions, high purity SFE-grade $\mathrm{CO}_{2}$ is not required due to its high cost. However the impurity and moisture level in various industrial grades of $\mathrm{CO}_{2}$ can accumulate and adversely effect instrumental performance. This accumulation of contaminants can also affect the analysis of trace and volatile lipid components, since analytical SFE tends to concentrate these contaminants during the collection stage. Such an accumulation of contaminates can ultimately interfere with the off-line analysis techniques, such as gas or liquid chromatography.

France et al. (1991) characterized several sources of $\mathrm{CO}_{2}$ as to their suitability for the SFE of ultra-trace components. They ultimately developed an on-line fluid cleanup system between the cylinder source and the fluid pumping modules which removed trace contaminants from the carbon dioxide. This system was later improved upon by Hopper et al. (1995) for the extraction of food items in the US Food \& Drug Administration total diet analysis. More recently, Micro Porous Oxides Science \& Technology, L.L.C (Oregon, Wisconsin, USA) has offered a $\mathrm{CO}_{2}$ purifier using a micro porous ceramic oxide catalyst for destroying impurities commonly found in $\mathrm{CO}_{2}$ (Zorn et al. 2000)

When extracting and separating lipid compounds using SFE or SFF one should avoid the use of helium headspace-padded $\mathrm{CO}_{2}$ cylinders. This technique, originally developed to avoid the use of circulating coolers with fluid pumps, introduces small quantities of helium into the $\mathrm{CO}_{2}$ phase in the pressurized cylinder. As shown by King et al. (1995b) and others (Raynie and Delaney 1994) the presence of helium in $\mathrm{CO}_{2}$ will reduce the solubility of lipids in $\mathrm{SC}-\mathrm{CO}_{2}$ from $33-50 \%$, depending on the chosen extraction pressure and temperature. The use of such a $\mathrm{CO}_{2}$ source can lead to lower lipid recoveries from sample matrices and hence inconsistent analytical results.

\section{CRITICAL PARAMETERS FOR SUCCESSFUL SFE}

Successful application of analytical SFE for lipid extractions and sample preparation require consideration of three areas: the characteristics of the sample matrix, sample matrix preparation prior to extraction, and choice of the extract collection method. For the first case, the level of anticipated extractable (i.e., lipid content) and moisture content are key factors affecting the analytical SFE process. Analytical SFE has been applied to sample matrices containing lipid levels as low as $1 \mathrm{wt} . \%$ and as high as $50 \mathrm{wt}$. \%. The challenge to the analyst is to assure in either case that the lipid content of the matrix is accessible to the SF and totally extracted. Polar lipids such as phospholipids have negligible solubility in neat $\mathrm{SC}-\mathrm{CO}_{2}$, and the addition of co-solvent such as ethanol is required to affect removal from a sample 
(Montanari et al. 1999). Both high and low lipid content samples may have to be dispersed with an extraction enhancer (Hopper and King 1992) as described below. Without such a provision, channelling of the extraction fluid may occur throughout the sample matrix, leading to incomplete extraction. A high moisture level in the sample matrix may also inhibit contact between the extraction fluid and the lipid- rich regions of the sample matrix. Therefore removal of the water by freeze or oven drying may be required for some sample types prior to SFE.

Sample preparation prior to SFE consists of the following: comminution of the sample if needed, minimizing the effect of water in the sample matrix, and dispersion of the sample matrix prior to SFE. Mechanical grinding of the sample prior to SFE to decrease the particle size will increase the mass transfer of the dissolved solutes (i.e., lipids), resulting in a faster extraction flux of the solutes (Snyder et al. 1984). Likewise, the use of sorbent mulling, e.g., matrix solid phase dispersion, MSPD (Barker and Hawley 1992) can effectively disrupt the sample matrix, releasing bound lipid moieties from the sample matrix.

Drying of the sample matrix can be affected by adding a drying agent to the sample matrix, but the choice of dessicant is critical in order to avoid caking of the sample matrix which could impede the extraction process. The choice of drying agent can be made by consulting the study of Burford et al. (1993) in which several common dessicants were evaluated with respect to their efficiency in analytical SFE. Figure 4 illustrates the impact of drying the sample matrix, i.e. a high moisture-containing smoked ham, on the recovery of its fat content. Note that the water content of the wet sample seriously impedes the removal of lipid from the sample matrix. Control of water during the SFE process is also

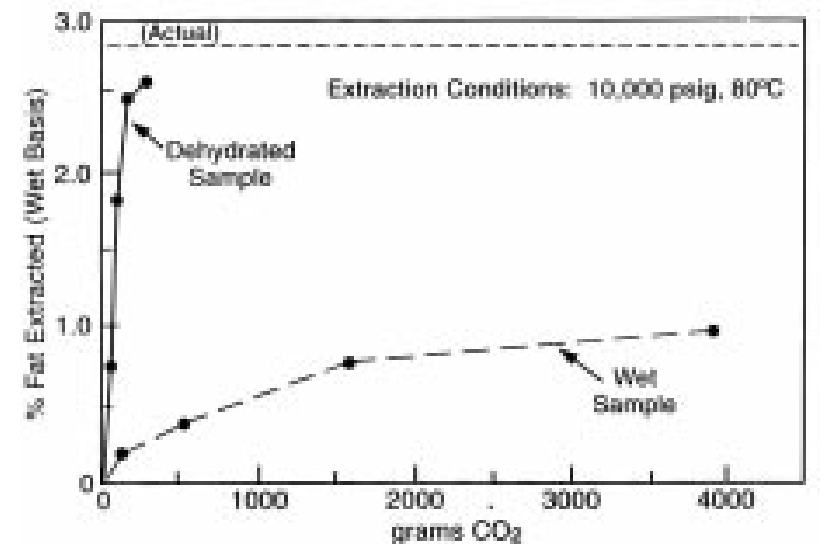

Figure 4

$\mathrm{SC}-\mathrm{CO}_{2}$ extraction of a smoked ham sample: effect of moisture content on recovery of fat and rate of extraction. important to minimize the plugging of restrictors, since the attendant Joule-Thompson effect present upon expansion of $\mathrm{SC}-\mathrm{CO}_{2}$ to atmospheric pressure can result in ice formation at the restrictor orifice, resulting impedance of fluid flow.

The use of pelletized celite, i.e., Hydro-matrix, when mixed with a lipid-containing matrix solves many of the sample matrix preparation problems noted above simultaneously (Hopper and King 1992). This patented concept uses large particle size diatomaceous earth to disperse many sample types very effectively, and is marketed by SFE instrumentation companies under various product designations. The addition of Hydromatrix will also adsorb approximately twice its weight in moisture, and hence can be used to prepare high water-containing samples for SFE successfully.

As noted by Taylor (1996), optimisation of the collection method for the resultant extract from SFE is often neglected, resulting in the false assumption that the SFE step was unsuccessful or incomplete. For the collection of lipid extracts, it would appear that the open vial or sorbent- filled collection vial are most frequently used; the latter frequently employing some type of sub- ambient cooling to retain volatile species. King and Zhang (2000) have modelled solute trapping in a open vessel in terms of the retention efficiency of the analyte being collected and shown that trapping efficiency is related to the relative vapour pressures of the solute (analyte) and the solvent (supercritical fluid). Since $\mathrm{CO}_{2}$ upon decompression has a large fugacity, it is not unusal for the ratio of solvent/solute vapour pressures to exceed $10^{3}$. Despite this favorable phase separation, it is best to use a collection vessel packed with a surface area material, i.e. glass beads or wool in order to avoid entrainment of target analyte in the escaping fluid (Eller and King 1996).

Analyte collection in a sorbent filled collection device has been utilized in analytical SFE for many years, and has been an integral component in older instrumentation that is no longer commercially produced (i.e. Hewlett Packard Model HP 7680 and Suprex Autoprep 44). This collection principle finds application in the SFE of lipids, primarily for trapping volatile and semi-volatile components, i.e., lipid degradation products (Snyder and King 1994). Successful application of this mode of collection requires an appreciation of the potential of analyte breakthrough off the collection sorbent as the extraction continues. Breakthrough characteristics for a number of common volatile compounds have been measured by gas-solid chromatography using $\mathrm{CO}_{2}$ as a carrier gas (Taylor et al. 1994), and have been shown to be considerable less then those found with helium as a carrier gas. This is a direct reflection of the enhanced interaction between low pressure $\mathrm{CO}_{2}$ and typical organic solutes; i.e. $\mathrm{CO}_{2}$ is 
a favourable medium for extracting volatile compounds at very low pressures.

This factor must be considered when using sorbent trapping devices in analytical SFE since breakthrough off the sorbent bed in the presence of decompressed $\mathrm{CO}_{2}$ can occur. Figure 5 shows the specific volume of fluid per gram of adsorbent $\left(\mathrm{V}_{\mathrm{g}}\right)$ at $25^{\circ} \mathrm{C}$, needed to displace various volatile organic compounds off Tenax TA, a popular sorbent collection medium, as a function of sorbate boiling point. An the prediction of breakthrough volume based on the boiling point of the volatile compound being collected. The dashed line represents the $\mathrm{V}_{\mathrm{g}}$, breakthrough volume for a SFE and collection at an expanded $\mathrm{CO}_{2}$ flow rate of $2 \mathrm{~L} / \mathrm{min}$ and $30 \mathrm{~min}$. extraction time, using 2 grams of Tenax TA sorbent. Note that under these extraction and collection conditions, most of the compounds having boiling points under $120^{\circ} \mathrm{C}$ would be lost in the effluent from the sorbent-filled collection device. This problem could be overcome by cooling the sorbent-filled collector to $-25^{\circ} \mathrm{C}$, which would allow retention of all of the compounds except one in the five classes cited in Figure 5. The effect of trapping temperature in analytical SFE has also been nicely demonstrated by Levy and Houck (1993) for the collection of hydrocarbons from diesel exhaust particulates.

\section{APPLICATION OF ANALYTICAL SFE TO FATS, OILS, AND LIPIDS}

In this section select examples of the application of analytical SFE for the extraction and sample preparation of lipid-containing samples will be discussed. Many of the chosen examples are from the author's research and methods development at USDA, however other examples are cited from literature. Some additional reviews that address the SFE of fats, oils, and lipids are provided by Hierro

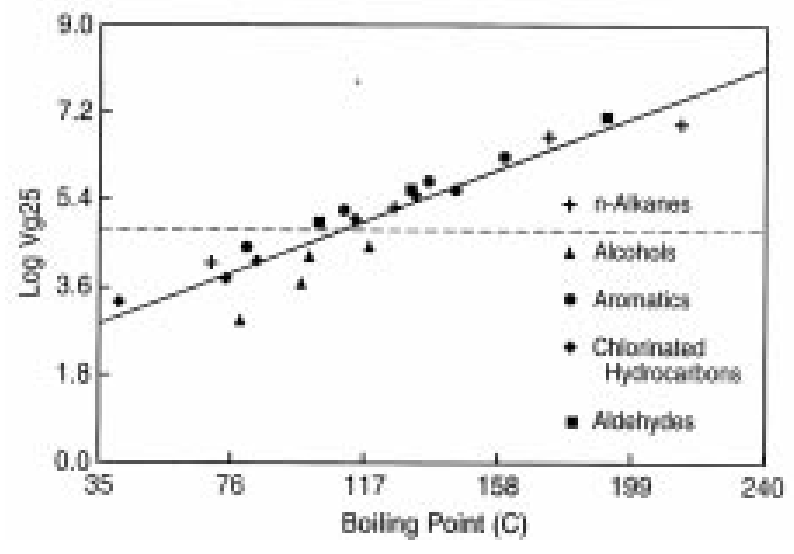

Figure 5

Sorbate (analyte) breakthrough volumes, $\mathrm{V}_{\mathrm{g}} 25$,versus analyte boiling point for various classes of compounds on Tenax-TA with carbon dioxide. and Santa-Maria (1992), Clifford and Walker (1996), and Eller and King (1996).

One of the successful and commercially important areas for analytical SFE is the determination of fat and oil levels in food and agricultural products. Traditional methods for fat analysis have incorporated a wide variety of solvents and pre-extraction preparation methods for different types of food matrices. The AOAC Official Methods of Analysis lists 28 different solvent extraction methods that promulgate the use of organic solvents. These determinations have to a large extent been conducted on Soxhlet-type apparatuses.

Experimental process studies conducted in our laboratories in the early 1980's allowed us to optimise the SFE conditions for removing vegetable oils from seed matrices (Friedrich and Pryde 1984; Snyder et al. 1984). These and additional processing studies for removing fat and cholesterol from meat matrices (King et al. 1993b) increased our knowledge as to how to prepare a high moisture-containing matrix for successful fat removal via SFE. Having such information and technique in hand permitted extension of the concept for analytical determination of fat and oil levels in a variety of food and agricultural matrices (Eller and King 1996).

The review by Eller and King (1996) summarizes many of the gravimetric-based SFE assays for fats in food and agricultural products. There are many examples which show the excellent agreement between SFE results and traditional solvent extraction methods based on gravimetry. As an example, Table IV compares the results attained using an analytical SFE method (Taylor et al. 1993) with those values obtained by a standard Soxhlet extraction procedure for the oil content of various seed types. The agreement is reasonably good and the precision of the analysis is equivalent to or better than the Soxhlet-based method in this particular case. However, gravimetric-based results can show a dependence on the extraction solvent chosen, the sample matrix, as well as the co-extraction of moisture and non-lipid moieties.

Table IV

Analytical-scale extraction of various seed oil commodities: SFE versus Soxhlet

\begin{tabular}{lcc}
\hline \multicolumn{1}{c}{ Sample } & \multicolumn{2}{c}{ Weight percent recovery $( \pm$ SD $)$} \\
\hline \multicolumn{1}{c}{ SFE $^{\mathrm{a}}$} & Soxhlet $^{\mathrm{b}}$ \\
\hline Soybean flakes & $20.6( \pm 0.2)$ & $20.5( \pm 0.2)$ \\
Canola & $39.8( \pm 0.5)$ & $40.5( \pm 0.5)$ \\
Wet-milled corn germ & $48.9( \pm 0.5)$ & $50.4( \pm 1.3)$ \\
\hline
\end{tabular}

$a_{n}=4 ; b_{n}=5$ 
Further, simple gravimetric-based analytical SFE assay for fats in foodstuffs can be prone to error, particularly if one accepts the new definitions and analytical protocols mandated by the Nutritional Labeling and Education Act of 1990 (DeVries and Nelson 1994). This new method for fat determination has created considerably more effort and complexity for the fat analyst since it is based on a pre-extraction hydrolysis and an elaborate gas chromatographic analysis of the methyl esters of the constituent fatty acids which comprise the fat moieties in the food matrix. This procedure in addition to the extraction of the sample presents a considerable challenge to the analyst in developing an equivalent SFE-based protocol.

To establish a baseline, a method was developed whereby all steps that were inclusive in the NLEA solvent based-extraction protocol were utilized in a procedure incorporating extraction with $\mathrm{SC}-\mathrm{CO}_{2}$ rather then the specified liquid solvent (King et al. 1996). This off-line SFE method utilized a sorbent disk to entrap the resultant lipid precipitate from a meat sample after acid hydrolysis of the meat sample, via filtration. A disk containing a fat precipitate was subsequently placed inside an extraction cell and the fat removed by SFE using $\mathrm{CO}_{2}$. Trials on two different commercial SFE units indicated that the technique was not instrument dependent. Further, comparison of the results from the SFE procedure with those obtained via the traditional solvent-based protocol were equivalent for nine different meat matrices representing different levels of fat and types of meat. This procedure however was exacting and difficult to reproduce in the hands of a unskilled analyst.

However another development, namely the enzymatic-catalysed production of methyl esters of vegetable oils by coupling the SFE step with a trans-esterification reaction conducted in the presence $\mathrm{SC}-\mathrm{CO}_{2}$, proved applicable to the problem posed by the NLEA method (Jackson and King 1996). In this case, seed oil samples could be readily dissolved in $\mathrm{SC}-\mathrm{CO}_{2} /$ methanol mixtures at pressures of $2500 \mathrm{psi}$ and a temperature of $50^{\circ} \mathrm{C}$ to quantitatively produce the methyl esters of fatty acid methyl esters (FAMES). This transformation was facilitated by passing the $\mathrm{SC}-\mathrm{CO}_{2} /$ methanol mixture containing the dissolved oil over a supported lipase (Novozym 435) derived from Candida antarctica, which was placed downstream from the lipid-containing sample in the extraction cell.

The excellent and reproducible yields of the FAMEs using the above method compared well to results achieved using a classical FAME derivatisation method, i.e. the $\mathrm{BF}_{3} /$ methanol method, indicating that the method was suitable for conducting NLEA-based fat analysis. When this off-line SFE FAME-based method was applied for fat analysis in meats, good agreement was obtained with those values derived from solvent-based NLEA methods (Snyder et al. 1996). This method was further refined and expanded by incorporating it into a automated sequential SFE/GC system in which the extraction/reaction were accomplished on an automated SFE system, the Hewlett Packard Model 7680 , using a robotic arm interface for transferring the derivatised extracts into the GC sampling tray for automated, overnight, unattended analysis. Results obtained on the above-mentioned meat samples using this system were also consistent with the values obtained by NLEA analysis. Additional studies by Snyder et al. (1997) on model lipid compounds, such as phospholipids and cholesteryl esters, showed that the enzymatic-catalysed reaction would work equally well for these more polar lipid compounds and their fatty acid contribution to the NLEA fat assay.

Further exploitation of the above combination of extraction/reaction chemistry in $\mathrm{SC}-\mathrm{CO}_{2}$ has been applied to oilseeds and cereal products. A particularly novel application of the SFE/SFR technique has been the measurement of fatty acid content of soapstock, a side stream product from the refining of vegetable oils (King et al. 1998b). Using the SFR/SFE method, equivalence to the official American Oil Chemists Society (AOCS) Method for fatty acid content in soapstock was found to be excellent. In addition, the method has reduced the total analysis time by $50 \%$ and solvent required in the analysis. For example, the AOCS method uses 575 $\mathrm{mL}$; of solvent, while the supercritical fluid extraction/reaction scheme using enzymatic catalysis requires only $1.8 \mathrm{~mL}$ of solvent.

The extraction of specific lipid components, such as cholesterol, can be accomplished with $\mathrm{SC}-\mathrm{CO}_{2}$ as reported in the literature (Ong et al. 1990; Froning et al. 1994; Boselli et al. 1997). The problem from an analytical perspective are the large number of co-extractives that also exhibit sufficient solubilities in $\mathrm{SC}-\mathrm{CO}_{2}$ which are co-extracted along with the desired solute (analyte). As noted previously, this frequently requires the application of sorbents to permit separation of the target analyte from the co-extracted lipids. This is a particular vexing problem when attempting to analyse the cholesterol content of foods.

One technique which we have developed called "inverse" SFE (King 1998c) is applicable to the above problem. In this case, a sorbent is used to retard the target analyte(s) of interest, and the interfering co-extractives are removed from the sample matrix first, usually with neat $\mathrm{SC}-\mathrm{CO}_{2}$. The desired analytes are then removed from the adsorbent by using a higher $\mathrm{CO}_{2}$ extraction density, or $\mathrm{SC}-\mathrm{CO}_{2}$ with a co-solvent. For example, we found that amino-bonded silicas (from SPE cartridges) will 
selectively retard sterols relative to other lipid components in the presence of $\mathrm{SC}-\mathrm{CO}_{2}$. Using a three-fold excess of sorbent to sample by weight in the extraction cell, we have been able to fractionate the triglycerides at $500 \mathrm{~atm}$. and $80^{\circ} \mathrm{C}$ away from cholesterol in the oil or food matrix. Then by using 6 vol. \% of methanol in $\mathrm{SC}-\mathrm{CO}_{2}$ for the same extraction time and conditions used for the neat $\mathrm{SC}-\mathrm{CO}_{2}$ extraction (60 min@2 ml/min), cholesterol can be eluted relative free of interfering lipids. Results from the capillary SFC (supercritical fluid chromatography) analysis of the extract fractions obtained from several commodity food items are shown in Table V. The recorded recoveries for cholesterol and accuracy relative to the nutritional labelling value are good using the "inverse" SFE method over a twenty-fold range of cholesterol concentration in the given food items.

The determination of fat soluble vitamins in foods is another area of application for analytical SFE. Initial studies in applying SFE for analysis of vitamins started as early as 1988, but further method development was limited over the ensuing decade (Schneiderman et al. 1988, 1997; Burri et al. 1997). Recently, Berg et al. (2000) and Turner et al. (2001) in conjunction with a European Union collaborative, have applied analytical SFE for the determination of vitamin $A$ and $E$ in a variety of food matrices. The study by Turner et al. (2001) has been extended using enzymatic catalysis in the presence of $\mathrm{SC}-\mathrm{CO}_{2} /$ cosolvent mixtures for the on-line hydrolysis

Table V

\section{Cholesterol recovery from various foods relative} to their label values

\begin{tabular}{lcc}
\hline \multicolumn{1}{c}{ Type of Food } & $\begin{array}{c}\text { \% Cholesterol } \\
\text { Recovery }\end{array}$ & $\begin{array}{c}\text { Label Value } \\
(\mathbf{m g})\end{array}$ \\
\hline Turkey breast luncheon meat & 74.5 & 10 \\
Braunschweiger & 100 & 100 \\
Salad dressing & 86.4 & 5 \\
\hline
\end{tabular}

Table VI

Recovery of vitamin A from different types of foods

\begin{tabular}{lc}
\hline \multicolumn{1}{r}{ Sample type } & \% Retinol recovery \\
\hline Milk powder & $102(2)$ \\
Infant formula & $79(13)$ \\
Liver paste (12\% fat) & $119(12)$ \\
Liver paste (23\% fat) & $104(12)$ \\
Minced pork meat & $103(19)$ \\
Minced beef meat & $98(21)$ \\
\hline
\end{tabular}

of vitamin A in a variety of food matrices. With an appropriate level of water, the lipase (Novozyme 435) hydrolyzes vitamin A to retinol, thereby avoiding the harsh chemical saponification step traditionally used in these vitamin assay procedures. Table VI reports the recoveries of vitamin $A$ as retinol relative to the values from the classical procedure. The hydrolysis and extraction were performed in-situ in the extraction cell by using a segmented bed in which the food sample is separated from the immobilized enzyme by a bed of Hydromatrix. The extraction/reaction conditions and their optimisation are discussed by Turner et al. 2001.

As noted in the introduction, there have been a number of applications of analytical SFE for the analysis of lipid or lipid-derived volatile and semi-volatile compounds. This is in part due to the relative benign extraction conditions which minimize thermal or oxidation by-products. In addition by applying SFE, the analyst can frequently extract higher molecular weight, semi- volatile compounds that are not readily accessible by competitive techniques ,thereby providing additional information. For example, Snyder and King (1994) contrasted the volatile/semi-volatile profiles obtained from a thermal desorption technique with those obtained by desorption using SFE. They found two important differences between the two techniques: (a) SFE desorption yielding higher molecular compounds not accessible via thermal desorption which could be used to further characterize the oxidative state of a seed oil, and (b) there was an absence of low molecular weight degradation products in the SFE desorption profile. The latter observation suggested that the conventional thermal-based desorption technique produced artifacts from the technique, i.e., headspace analysis purge and trap, that were not in the original sample. The absence or minimal appearance of volatiles having a carbon number less than $\mathrm{C}_{6}$ at equivalent extraction (desorption) temperatures strongly supported this conclusion. Another consistent advantage in using SFE for volatiles analysis is that the a large quantity of volatiles/ semi-volatiles can be extracted more rapidly then when using competitive techniques.

Analytical SFE of lipid-derived volatiles/semivolatiles has been used to study several problems. Morello (1994) applied analytical SFE to characterize aroma volatiles in extruded oat cereals, noting the increased intensity of hexanal, 2,4 decadienal, and pyrazine compounds in the SFE extract. We have achieved similar results when extracting soybean and canola oils, and for the isolation of aroma components from roasted peanuts. Seitz et al. (1999) characterized the volatiles obtained from whole and ground grain samples using two methods: SFE and a direct helium purge technique. The extracted compounds were characterized by off-line GC-MS/R (gas chromatography- 
mass spectrometry/infrared spectroscopy). The extraction of volatiles from ground grain by SFE was optimal at extraction pressures less than $14 \mathrm{MPa}$ and in the temperature range from $50-90^{\circ} \mathrm{C}$, however the direct heluium purge method yielded a greater quantity of volatiles for analysis. However extraction using SFE proved optimal with respect to aldehydes, for 2,3-butanediols, and halogenated anisoles.

A particularly novel application of analytical SFE related to lipid technology is its use to detect irradiated foodstuffs. In a landmark study, Lembke et al. (1995) used SFE and GC-MSD (mass selective detector) to characterize the hydrocarbon patterns and appearance of cyclic ketones that were characteristic of foods exposed to irradiation. By using a low extraction fluid density, $0,25 \mathrm{~g} / \mathrm{mL}$, the marker hydrocarbons could be readily extracted avoiding the SFE of higher molecular weight fatty acid moieties. Among the irradiated foods extracted were pork meat, duck breast, pastachio nuts, and chicken soap. Using a similar method, Hampson and coworkers (1996) used SFE to identify the presence of marker hydrocarbons in irradiated meats.

Both Tewfik et al. (1998) and Stewart et al. (2001) used analytical SFE to extract the 2-alkylcyclobutanone moieties from irradiated foods. Exposure of foods to irradiation yields straight chain hydrocarbons that are one carbon number less than the parent fatty acid, i.e., odd numbered fatty acids that are reliable markers for food exposure to irradiation. The 2-alkyl cyclobutanones arise from fatty acids of the same carbon number and have the alkyl group in a ring position, therefore fatty acids such as palmitic, stearic, oleic, and linoleic can yield trace levels of the alkylcyclobutanones. As shown in Table VII (Stewart et al. 2001), extraction using SFE shows an increasing concentration of alkylcyclobutanones with irradiation dosage for three

Table VII

Concentrations of 2-Dodecylcyclobutanone (2-DCB) and 2-Tetradecylcyclobutanone(2-TCB) Isolated by SFE from Irradiated Foods

\begin{tabular}{lccc}
\hline Foodstuff & $\begin{array}{c}\text { Irradiation } \\
\text { dose }\end{array}$ & 2-DCB & 2-TCB \\
& 0.5 & 0.02 & 0.01 \\
Chicken meat & 2.5 & 0.10 & 0.03 \\
Liquid whole egg & 5.0 & 0.14 & 0.05 \\
& 0.5 & 0.06 & 0.03 \\
& 2.5 & 0.57 & 0.36 \\
Ground beef & 5.0 & 1.23 & 0.57 \\
& 0.5 & 0.06 & 0.06 \\
& 2.5 & 0.35 & 0.36 \\
& 5.0 & 0.63 & 0.57 \\
\hline
\end{tabular}

${ }^{1}$ Concentrations in micrograms/10 gram of sample. commodity food items. It should be noted that the analytical method using SFE and GC/MS for cyclobutanone detection takes approximately six hours to perform, while the standard method takes two days to arrive at the same results.

As noted in the introduction, this review has not attempted to treat the application of on-line SFE for lipid extraction and sample preparation in any great detail. These methodogies have to a large extent been practiced in the academic sector are not routinely used for lipid sample preparation, in part due to the lack of commercial instrumentation. The excellent tome by Ramsey (1998) is recommended for those interested in more detail on this SFE methodology and its applications. However two techniques should be mentioned briefly because of their relevance to lipid chemistry. Hansen and Artz (1994) applied SFE to fractionate thermally oxidized canola oil followed by analysis of the fractions with high performance size exclusion chromatography. This permitted the determination of dimer and trimer formation from the parent fatty acids in canola oil. Liescheski (1996a, 1996b) has coupled infrared spectroscopy on-line with SFE to determine the iodine number of edible oils as well as the trans fatty acid content of vegetable oils. In the former case, it was found that the symmetric $\mathrm{CH}_{2}$ stretching frequency could be linearly correlated with the iodine number. Direct transfer of the dissolved lipids to an on-line IR cell from an Isco SFX 2-10 unit was used in the reported experiments. The author also used the SFE-IR tandem technique to determine the total lipid content of milled rice flour.

A measure of the acceptance of a new technique or method is frequently confirmed by a collaborative study or peer verification. Through the efforts of Les Myer, currently with Leco Corporation (St. Joseph, $\mathrm{MI}$ ), a new official method, Am3-96, "Oil in Oilseeds: Supercritical Fluid Extraction Method" was confirmed in 1996 (King and O'Farrell 1996). In this collaborative study, SFE extractions were performed on five oilseed types: soybean, cottonseed, canola, sunflower, and safflower. Both extractions with neat $\mathrm{CO}_{2}$ at 7500 psi and $100^{\circ} \mathrm{C}$ and SC-CO $/ 15$ vol. \% ethanol under the same conditions at 30 and 60 min., respectively were performed in 17 laboratories on the above oilseeds. The two extractions steps were designed to emulate AOCS Official Method Ac 3-44, a Butt-type extraction-based method, and a AOCs methodology (AOCS 2-93) which provides more exhaustive extraction of all of the lipids in the seed oils, i.e., phospholipids. This method has also received co-sanction by AOAC International.

Matthaus and Bruhl (1999) and Bruhl and Matthaus (1999) conducted a study to compare SFE with DGF standard method B-15 (87). This study was somewhat unique in that the resultant extracts were analysed for the tocopherol, free fatty acid, and 
diglyceride contents. They found that the highest yields of lipids and tocopherol content were achieved with the SFE method. The latter finding led them to conclude that because of the high retention of the original tocopherol content, that the SFE was a more be benign technique. They found good correspondence between the total oil values obtained DGF standard method and the SFE method, however the SFE method required only 40 min., while the DGF method took over four hours to achieve a comparable result.

Another study worth noting is that of Berg and coworkers (1997) who developed a SFE method for total fat and lipid classes in meats. Extractions were performed at 370 bar, $50^{\circ} \mathrm{C}$, using $8 \%$ ethanol modifier, $4 \mathrm{ml} / \mathrm{min}$ dynamic flow of liquid $\mathrm{CO}_{2}$ for 30 min. on $0.5 \mathrm{~g}$ of sample. Extraction was aided by the addition of one $\mathrm{mL}$ of cyclohexane to the sample mixed with 1 gram of Hydromatrix. Equivalent extraction results were obtained using the SFE method with those achieved with two other solvent extraction methods on prok loin, sausages of varying fat level, and fermented entrecote. Somewhat different conclusions regarding the equivalence of SFE to other standard methods were ascertained by Simoneau et al. (2000) when analysing for the fat content of chocolate and cocoa products. SFE in this case tended to give somewhat lower results when compared to an acid digestion-Soxhlet extraction procedure, and the relative standard deviations tended to be higher when using the SFE method.
Recently a method entitled, "Determination of Crude Fat in Meat by Supercritical Fluid Extraction: Direct Method" by Chandrasekar (2001) was peer verified for twelve different types of meat samples. The fat content of these sample matrices ranged from 6 - 28 weight \%. SFE was performed at $9000 \mathrm{psi}$ and $100^{\circ} \mathrm{C}$ using an expanded $\mathrm{CO}_{2}$ flow rate of 1.3 $\mathrm{L} / \mathrm{min}$. Using direct gravimetry to weight the resultant extracts yielded repeatability and reproducibility values less than 3 , while the mean accuracy ranged from -0.22 to -1.41 when compared to AOAC Method 960.39 .

In conclusion it would appear overall that SFE-based methods have a promising future in analytical lipid chemistry. The results reported for the above methods and the previously cited European Union study on fat soluble determinations illustrate the wide application potential for SFE employing $\mathrm{SC}-\mathrm{CO}_{2}$. More collaborative and peer validated methods will be needed in the future to fulfill instrumentation vendors projections for SFE. However, one food company in the United States now employs a large number of analytical supercritical fluid extractors for routine fat determinations in a production plant environment. In this case, the SFE results are used to calibrate on-line infrared analyzer used in food production lines.

Finally, it was remarked earlier that analytical SFE can be employed to considerable advantage as an aid in optimising and testing the feasibility of using

Table VII

Examples of analytical SFE instrumentation utilized in non-analytical applications

\begin{tabular}{|c|c|c|}
\hline & Instrument & Application \\
\hline SFX2-10 & & Optimization of Taxol Extraction from Yew Wood \\
\hline SFX2-10 & & Study of Simple Enzyme Esterification Reactions \\
\hline SFX2-10 & & Sterol Ester Fractionation Using Sorbents \\
\hline SFX2-10 & & Feasibility of Aceylated Tocopherols \\
\hline SFX2-10 & & Enzymatic-Initiated Synthesis of Sterol Esters \\
\hline HP-7680P & & SFE and Methylation of Phospholipids and Steryl Esters \\
\hline HP-7680P & & Evaluation of Enzyme Catalytic Activity in SC-CO \\
\hline SFX 3560/Speed & & Optimization of SFE of Cedarwood Oil in SC- $\mathrm{CO}_{2}$ and $\mathrm{LCO}_{2}$ \\
\hline SFX 3560 & & Sorbent Selection for Preparative SFC of Phospholipids \\
\hline SFX 3560 & & SFE/SFC for Enrichment of Steryl Esters from Corn Bran \\
\hline SFX 3560 & & $\mathrm{SC}-\mathrm{CO}_{2}$ - Extraction of Pheromone Components from Fir Needles \\
\hline SFX 3560 & & Sterol and Steryl Ester Enrichment from Corn Bran Oil \\
\hline SFX 3560 & & Feasibility of Enzymatic-Initiated Acetylation of Cedrol \\
\hline Speed & & Enzyme Enantioselectivity Studies in SC- $\mathrm{CO}_{2}$ \\
\hline Speed & & Solute Solubility Studies in Subcritical Water \\
\hline Speed & & Batch, Stirred Cell - Ferrulate Ester Synthesis \\
\hline Speed & & Solubility Studies in Binary Fluid Mixtures \\
\hline Speed/SFX 2-10 & & Flow Reactor Studies - Hydrogenation/Transesterification \\
\hline Speed & & Subcritical Water Extraction \\
\hline
\end{tabular}


SFE or supercritical fluids for non-analytical applications, i.e., to investigate the potential for scaling up SFE for industrial application. We have utilized instrumentation designed for analytical SFE extensively for the above purpose in our laboratories. Using automated analytical SFE instrumentation for such purposes allows the rapid assessment as to whether a SFE or SFF will work at minimal expense and time. This combinatorial approach to process design has been recently discussed by King (2001) as applied to the processing of fats and oils. Table VIII lists some of the uses of analytical SFE instrumentation in process development. Note that the commercial SFE instrumentation discussed previously can be applied to solving a wide variety of problems that encompass extractions, fractionations, and even reactions in critical fluid media. Such demonstrated utility further justifies the cost of the instrumentation and provides a synergism between analytical research and process development which utilize supercritical fluids.

\section{REFERENCES}

Barker, S., Hawley, R. (1992). Efficient biological analysis using MSPD. Am. Lab. 24, 42-43.

Bartle, K.D., Clifford, A.A., Hawthorne, S.B., Langenfeld, J.J., Miller, D.J., Robinson, R. (1990). A model for dynamic extraction using a supercritical fluid. $J$. Supercrit. Fluids, 3, 143-149.

Berg, H., Magard, M., Johansson, G., Mathiasson, L. (1997). Development of a supercritical fluid extraction method for the determination of lipid classes and total fat in meats and its comparison with other methods. $J$. Chromatogr. A, 785, 345-352.

Berg, H., Turner, C., Dahlberg, L., Mathiasson, L. (2000). Determination of constituents in food based on SFE application to vitamin $\mathrm{A}$ and $\mathrm{E} \mathrm{I}$ meat and milk. $\mathrm{J}$. Biochem. Biophys. Meth., 43, 391-401.

Boselli, E., Caboni, M.F., Lercker, G. (1997). Determination of free cholesterol from dried egg yolk by on-line coupling of supercritical fluid extraction with solid phase extraction. Z.Lebensm. Unters. Forsch A, 205, 356-359.

Bruhl, L., Matthaus, B. (1999). Extraction of oilseeds by SFE - a comparison with other methods for the determination of the oil content. Fresenius J. Anal. Chem., 364, 631-634.

Burford, M.D, Hawthorne, S.B., Miller, D.J. (1993). Evaluation of drying agents for off-line supercritical fluid extraction. J. Chromatogr. A., 657, 413-418.

Burri, B.J., Niedlinger, T.R., Lo, A.O., Kwan, C., Wong, M.R. (1997). Supercritical fluid extraction and reverse-phase liquid chromatography methods for vitamin $A$ and beta-carotene. Heterogeneous distribution of vitamin $A$ in the liver. J. Chromatogr. A, 762, 201-206.

Chandrasekar, R. (2001). Determination of crude fat in meat by supercritical fluid extraction: direct method, PVM 3, 2000. J. AOAC Int., 84, 466-471.

CliffordA.A., Walker, D.F.G. (1996). Analytical Supercritical Fluid Extraction for Oil and Lipid Analysis in Supercritical Fluid Technology in Oil and Lipid Chemistry, Chap. 19, pp. 387-428, J.W. King and G.R. List (eds.), AOCS Press, Champaign, IL.
DeVries, J.W., Nelson, A.L. (1994). Meeting analytical needs for nutritional labeling. Food Tech. 48, 73-79.

Eller, F.J., King, J.W. (1996). Determination of fat content in foods by analytical SFE. Sem. Food Anal. 1, 145-165.

France, J.E., King, J.W., Snyder, J.M. (1991). Supercritical fluid-based cleanup technique for the separation of organochlorine pesticides from fats. J. Agric. Food Chem. 39, 1871-1874.

Friedrich, J.P., Pryde, E.H. (1984). Extraction of lipid-bearing materials and characterization of the products. J. Am. Oil Chem. Soc. 61, 223-228.

Froning, G.W., Fieman, F., Wehling, R.L., Cuppett, S.L., Niemann, L. (1994). Supercritical carbon dioxide extraction of lipids and cholesterol from dehydrated chicken meat. Poultry Sci., 73, 571-575.

Hampson, J.W., Jones, K.C., Foglia, T.A., Kohout, K.M. (1996). Supercritical fluid extraction of meat lipids: an alternative approach to the identification of irradiated meats. J. Am. Oil Chem. Soc., 73, 717-721.

Hansen, S.L., Artz, W.E. (1994). Supercritical fluid fractionation of thermally oxidized canola oil. J. Am. Oil Chem. Soc., 71, 615-618.

Hawthorne, S.B., King, J.W. (1999). Principles and Practice of Analytical SFE in Practical Supercritical Fluid Chromatography and Extraction. M. Caude and D. Thiebaut (Eds.), Harwood Academic, Chur, Switzerland, pp. 219-282.

Hierro, M.T.G., Santa-Maria, G. (1992). Supercritical fluid extraction of vegetable and animal fats with $\mathrm{CO}_{2}-\mathrm{a}$ mini review. Food Chem., 45, 189-192.

Hopper, M.L. King, J.W. (1992). Supercritical fluid extraction enhancer. U.S. Patent 5,151,188 (29-9-92).

Hopper, M.L., King, J.W., Johnson, J.H., Serino, A.A., Butler, R.J. (1995). Supercritical fluid extraction (SFE): multivessel extraction of food items in the FDA total diet study (TDS). J. Assoc. Off. Anal. Chem. Int., 78, 1072-1079.

Jackson, M.A., King, J.W. (1996). Methanolysis of seed oils in flowing supercritical carbon dioxide. J. Am. Oil Chem. Soc. 73, 353-356.

King, J.W. (1989). Fundamentals and applications of supercritical fluid extraction in chromatographic science. J. Chromatogr. Sci., 27, 355-364.

King, J.W. and Friedrich, J.P. (1990). Quantitative correlations between solute molecular structure and solubility in supercritical fluids. J. Chromatogr., 517, 449-458.

King, J.W. (1993a). Analysis of fats and oils by SFC and SFE. INFORM. 4, 1089-1098.

King, J.W., Johnson, J.H., Orton, W.L., O'Connor, P.L., Novakofski, J., Carr, T.R. (1993b). Effect of supercritical carbon dioxide extraction on the fat and cholesterol content of beef patties. J. Food Sci. 58, 950-952, 958.

King, J.W. (1995a). Analytical-process supercritical fluid extraction: a synergestic combination for solving analytical and laboratory scale problems. Trends Anal. Chem.,14, 474-481.

King, J.W., Johnson, J.H., Eller, F.J. (1995b). Effect of supercritical crabon dioxide pressurized with helium on solute solubility during supercritical fluid extraction. Anal. Chem., 67, 2288-2291.

King, J.W., Favati, F., Taylor, S.L. (1996a). Production of tocopherol concentrates by supercritical fluid extraction and chromatography. Sep. Sci. Tech., 31, 1843-1857.

King, J. W., Eller, F. J., Snyder, J. M., Johnson, J. H., McKeith, F. K., Stites, C. R. (1996b). Extraction of fat from ground beef for nutrient analysis using analytical supercritical fluid extraction. J. Agric. Food Chem. 44, 2700-2704. 
King, J.W., O'Ferrell, W.V. (1996c). SFE -new method to measure oil content. INFORM, 8 (10), 1047-1051.

King, J.W. (1997). Critical Fluids for Oil Extraction in Technology and Solvents for Extracting Oilseeds and Petroleum Oils, Chap. 17, pp. 283-310, P.J. Wan and P.J. Wakelyn (Eds.), AOCS Press, Champaign, IL.

King, J.W. (1998a). Analytical supercritical fluid techniques and methodology: conceptualization and reduction to practice. J. Assoc. Off. Anal. Chem. Int., 81, 9-17.

King, J.W., Taylor, S.L., Snyder, J.M., Holliday, R.L. (1998b). Total fatty acid analysis of vegetable oil soapstocks by supercritical fluid extraction/reaction. J. Am. Oil Chem. Soc., 75, 1291-1295.

King, J.W. (1998c). Integration of sample cleanup methods into analytical supercritical fluid extraction. Am. Lab., 30 (8), 46-58.

King, J.W., Zhang, Z. (2000). Theoretical optimization of analyte collection in analytical supercritical fluid extraction. Chromatographia, 51, 467-472.

King, J.W. (2001). Combinatorial-based critical fluid analysis as applied to the processing and analysis of fats and oils. Abstracts of the 92nd Annual AOCS Meeting. Minneapolis, MN, Abstract S5

Lee, M.L., Markides, K., Eds. (1990). Analytical Supercritical Fluid Chromatography and Extraction, Chromatography Conferences, Provo, UT

Levy, J.M., Houck, R.K. (1993). Developments in off-line collection for supercritical fluid extraction. Am. Lab., 25 (4), 36R-36Y.

Lembke, P., Bornert, J., Engelhardt, H. (1995). Characterization of irradiated food by SFE and GC-MSD. J. Agric. Food Chem., 43, 38-45.

Liescheski, P.B. (1996a). Supercritical fluid extraction coupled to infrared spectroscopy for iodine number analysis of edible oils. J. Agric. Food Chem., 44, 823-828.

Liescheski, P.B. (1996b). Supercritical fluid extraction coupled directly to infrared spectroscopy for the analysis of lipids in foods. Sem. Food Anal., 1, 85-100.

Luque de Castro, M.D., Valcarel, M., Tena, M.T. (1994). Analytical Supercritical Fluid Extraction, Springer-Verlag, Berlin.

Matthaus, B., Bruhl, L. (1999). Comparison of a supercritical fluid extraction method for the extraction of oilseeds with the DGF standard method B -I 5 (87). Fett/Lipid, 101, 203-206.

Maxwell, R.L., Parks, O.W., Piotrowski, G. (1992). Improved SFE recovery of trace analytes from liver using an integral micrometering valve - SPE column holder assembly. J. High Resolut. Chromatogr., 15, 807-811.

Montanari, L., Fantozzi, P., Snyder, J.M., King, J.W. (1999). Selective extraction of phos-pholipids with supercritical carbon dioxide and ethanol. J. Supercrit. Fluids, 14, 87-93.

Morello, M.J., (1994). Isolation of Aroma Volatiles from an Extruded Oat Ready-to-Eat Cereal in Thermally Generated Flavors: Maillard, Microwave, and Extrusion Processes, pp. 95-101,T.H. Parliament, M.J. Morello, and R.J. McGorrin (Eds.), American Chemical Society, Washington, DC

Ong, C.P., Ong, H.M., Li, S.F., Lee, H.K. (1990). The extraction of cholesterol from solid and liquid matrices using supercritical CO 2 . J. Micocol. Sep., 2, 69-73.

Ramsey, E.D. (1998). Analytical Supercritical Fluid Extraction Techniques, Kluwer Academic, Dordrecht.

Raynie, D.E., Delaney, T.E. (1994). Effect of entrained helium on the kinetics of supercitical extraction with carbon dioxide. J. Chromatogr. Sci., 32, 298-300.
Schneiderman, M.A., Sharma, A.K., Mahanama, K.R.R., Locke, D.C. (1988). Determination of vitamin $K_{1}$ in powdered infant formulas using supercritical fluid extraction and liquidChromatography with electrochemical detection. J. Assoc. Off. Anal. Chem., 71, 815-817.

Schneiderman, M.A., Sharma, A.K., Locke, D.C. (1997). Determination of vitamin A palmitate in cereal products using supercritical fluid extraction and liquid chromatography with electrochemical detection. $J$. Chromatogr. A, 765, 215-220.

Seitz, L.M., Ram, M.S., Rengarajan, R. (1999). Volatiles obtained from whole and ground grain samples by supercritical carbon dixoide and direct helium purge methods: observations on 2,3- butanediols and halogenated anisoles. J. Agric. Food Chem., 47, 1051-1061.

Simoneau, C., Naudin, C., Hannaert, P, Anklam, E. (2000). Comparison of classical and alternative extraction methods for the quantitative extraction of fat from plain chocolate and the subsequent application to the detection of added foreign fats to plain chocolate formulations. Food Res Int., 33, 733741.

Snyder, J.M., Friedrich, J.P., Christianson, D.D. (1984). The effect of moisture and particle size on the extractability of oils from seeds with supercritical $\mathrm{CO}_{2}$. J. Am. Oil Chem. Soc. 61, 1851-1856.

Snyder, J.M. and King, J.W. (1994). Oilseed volatile analysis by supercritical fluid and thermal desorption methods. J. Am. Oil Chem. Soc., 71, 261-265.

Snyder, J. M., King, J. W., and Jackson, M. A. (1996). Fat content for nutritional labeling by supercritical fluid extraction and on-line lipase catalyzed reaction. $\mathrm{J}$. Chromatogr. A 750,201-207.

Snyder, J. M., King, J. W., and Jackson, M. A. (1997). Analytical supercritical fluid extraction using lipase-catalysis: Conversion of different lipids to methyl esters and effect of moisture. J. Am. Oil Chem. Soc. 74, 585-588.

Snyder, J.M., King, J.W., taylor, S.L., Neese, A.L. (1999). Concentration of phystosterols for analysis by supercritical fluid extraction. J. Am. Oil Chem. Soc., 76, 717-721.

Stahl, E., Quirin, K.-W., Gerard, D. (1987). Dense Gases for Extraction and Refining.Springer-Verlag, Heidelberg.

Stewart, E.M., McRoberts, W.C., hamilton, J.T.G., Graham, W.D. (2001). Isolation of lipid and 2-alkylcyclobutanones from irradiated foods by supercritical fluid extraction. J. AOAC Int., 84, 976-986.

Taylor, L.T. (1996). Supercritical Fluid Extraction, John Wiley, New York.

Taylor, S. L., King, J. W., and List, G. R. (1993). Determination of oil content in oilseeds by analytical supercritical fluid extraction. J. Am. Oil Chem. Soc. 70, 437-439.

Taylor, S.L., King, J.W., Abel, S.A. (1994). Using inverse gas chromatographic measurements for the optimization of collection conditions in analytical SFE. Abstracts 5th International Symposium on SFC and SFE, Baltimore, MD, Abstr. D-16.

Taylor, S.L., Eller, F.J., King, J.W. (1997). A comparison of oil and fat content in oilseeds and ground beef using supercritical fluid extraction and related analytical techniques. Food Res. Int., 30, 365-370.

Taylor, S.L., King, J.W., Montanari, L., Fantozzi, P., Blanco, M.A. (2000). Enrichment and frac-tionation of phospholipid concentrates by supercritical fluid extraction and chromatography. Ital J. Food Sci., 12, 65-76. 
Turner, C., King, J.W., Mathiasson, L. (2001). On-line supercritical fluid extraction/enzymatic hydrolysis of vitamin A esters. A new simplified approach for the determination of vitamins $A$ and $E$ in food. J. Agric. Food Chem., 49, 553-558.

Tewfik, I.H., Ismail, H.M., Sumar, S. (1998). A rapid supercritical fluid extraction method for the detection of 2 -alkylcyclobutanones in gamma-irradiated beef and chicken. Lebens.-Wiss u.-Technol., 31, 366-370.
Wenclkawiak, B., Ed. (1992). Analysis with Supercritical Fluids: Extraction and Chromatography, Springer-Verlag, Berlin.

Zorn, M.E., Noll, R.J., Anderson, M.A., Sonzogni, W.C. (2000). In-line catalytic purification of carbon dioxide used in analytical-scale supercritical fluid extraction. Anal. Chem., 72, 631-633. 